\title{
SDC
}

SOLENOIDAL DETECTOR NOTES

\section{Measurements of Radiation Dose Using Radiochromic Film}

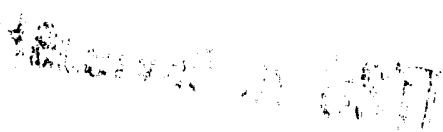

\author{
D. J. Jankowski and J. Proudfoot \\ High Energy Physics Division
}

Argonne National Laboratory, Argonne, Illinois 60439

\section{MASTER}

DISTRIBUTION OF THIS DOCUMENT IS UNLIMATED

24 November 1992

\section{DISCLAIMER}

This report was prepared as an account of work sponsored by an agency of the United States Government. Neither the United States Government nor any agency thereof, nor any of their employees, makes any warranty, express or implied, or assumes any legal liability or responsibility for the accuracy, completeness, or usefulness of any information, apparatus, product, or process disclosed, or represents that its use would not infringe privately owned rights. Reference herein to any specific commercial product, process, or service by trade name, trademark, manufacturer, or otherwise does not necessarily constitute or imply its endorsement. recommendation, or favoring by the United States Government or any agency thereof. The views and opinions of authors expressed herein do not necessarily state or reflect those of the United States Government or any agency thereof. 
Measurement of Radiation Dose using Radiochromic Film*

D. J. Jankowski, J. Proudfoot

Argonne National Laboratory

\begin{abstract}
We have irradiated samples of radiochromic film to doses between 0.005 and $1 \mathrm{Mrad}$ in a $\mathrm{Co}^{60}$ facility at ANL. The doses computed using the manufacturer's calibration curves for the absorption at 600 and $510 \mathrm{~nm}$ have been compared with the dose obtained from ion chamber measurements. Excellent agreement is obtained and high precision can be maintained by baseline measurement of the films prior to irradiation, appropriate choice of film and wavelength used.
\end{abstract}

\title{
1. Introduction
}

Many groups, both inside SDC and elsewhere, have been using radiochromic film to monitor radiation dose. In general these groups have decided to use films supplied by Far West Technologies. We here at Argonne have used these films in our radiation damage measurements to plastic scintillator and as a result of discussions with collaborators in FSU decided to verify the manufacturer's calibration curves. For these experiments we used a $\mathrm{Co}^{60}$ facility at Argonne with uniform radiation fields and the capability to perform both low and high dose irradiation (varying from 2100 to $62000 \mathrm{Rad} / \mathrm{min}$ ). The facility has in the past been used for biological experiments and with field maps and ion chamber measurements provided the accumulated dose to absolute accuracy of $3 \%$. The absorbed energy was corrected to absorbed dose using human tissue factors.

\section{Film Measurements}

To cover the full dose range from 0.005 to $1 \mathrm{MRad}$, we evaluated two types of radiation sensitive film supplied by Far West Technologies : radiochromic film( FWT 60-00) and GaFchromic film (DM 100). FWT 60-00 yields sensitivity in the range 0.4 to 60 Mrads and DM 100 yields sensitivity in the range 0.004 to $0.2 \mathrm{MRad}$. The optical absorption in these films is proportional to the absorbed dose. The radiation induced absortion absorption was measured by subtracting the observed absorption before irradiation from that observed after irradiation on a sample by sample basis at two wavelengths $(600$ and $510 \mathrm{~nm})$ using a simple photometer (FWT-92 Radiochromic Reader). This was converted to absorbed dose using calibration curves provided by the manufacturer since these calibration curves vary somewhat with film batch due to thickness variations and in addition include effects from non-linear response near the ends ot the ranges of sensitivity. Typically 4 films of approximately $1 \times 1 \mathrm{~cm}^{2}$ were measured at each dose value. Errors in reading the optical density were within the reading accuracy of the photometer ( 1 part ir: 1000). The

* Work supported by the U.S. Department of Energy, Division of High Energy Physics, Contract W-31-109-ENG-38. 


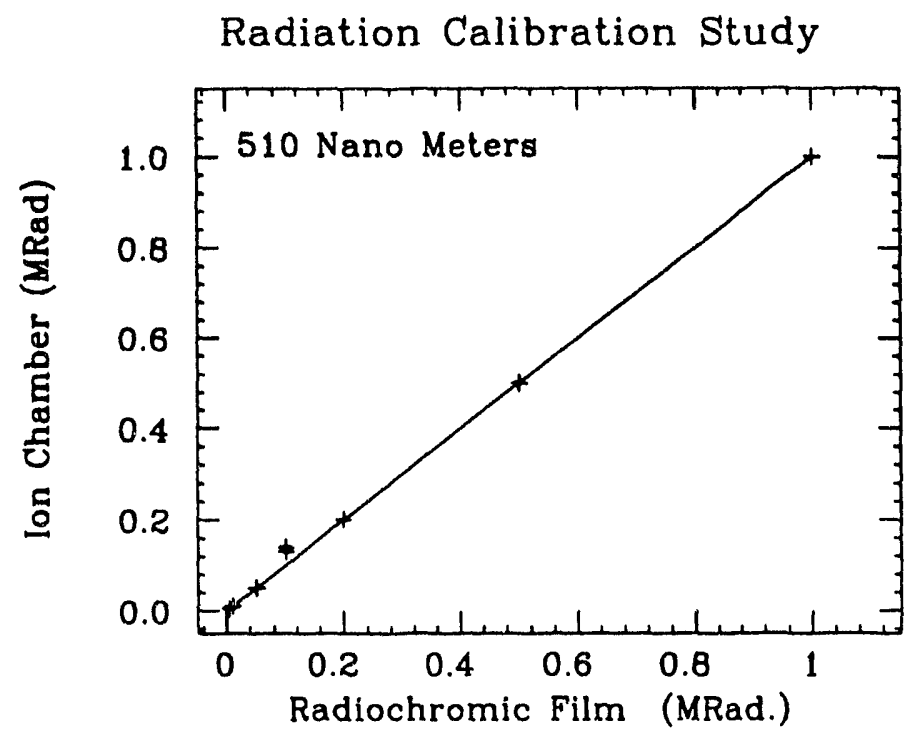

Figure 1: Absorbed $\mathrm{Co}^{60}$ dose measured using optical absorption at 510nm in radiochromic film compared to that obtained from ion chamber data. The points below $0.4 \mathrm{Mrad}$ were obtained using GaFChromic Film.

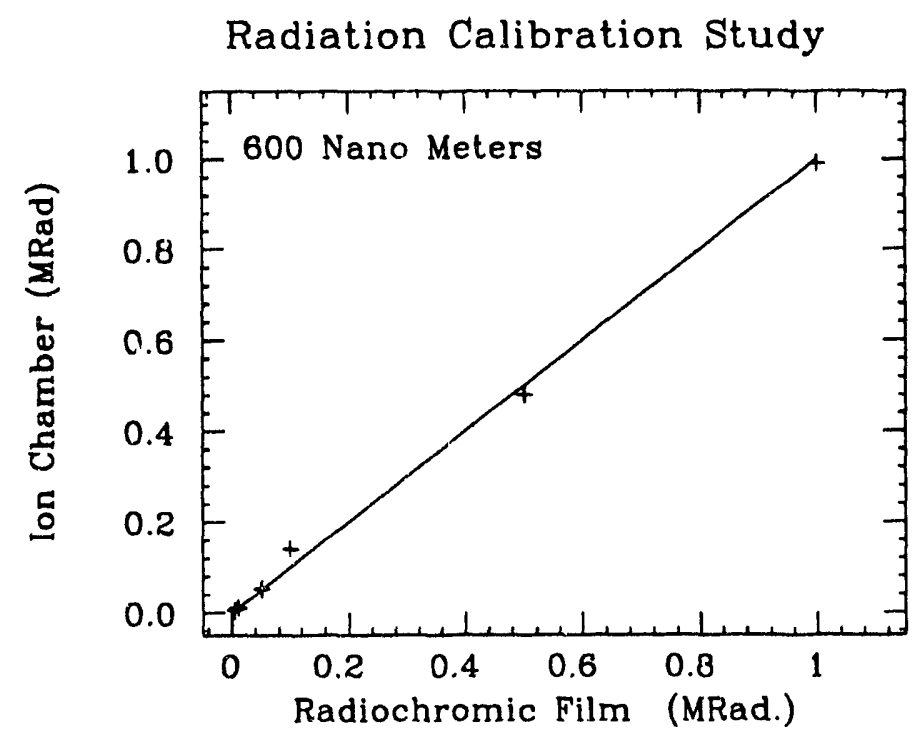

Figure 2: Absorbed $\mathrm{Co}^{60}$ dose measured using optical absorption at $600 \mathrm{~nm}$ in radiochromic film compared to that obtained from ion chamber data. The points below $0.4 \mathrm{MRad}$ were obtained using GaFChromic film. 
point by point reproducibility was approximately $1 \%$ contributing a corresponding error in the predicted dose. Figures 1 and 2 show the dose given by the film densities compared to that provided by ion chamber measurements for readout wavelengths of 510 and $600 \mathrm{~nm}$ respectively. The errors shown are a combination of photometer reading reproducibility and calibration graph reading error and were characterised by the rms of the set of individual measurements made at each point. For both wavelengths we see good agreement between the two different estimates of absorbed dose.

\section{Conclusions}

We have the precision with which two types of radiation sensitive film supplied by Far West Technologies measure absorbed dose by comparing the dose given by optical density measurements on the films with that from ion chamber measurements. The two methods are in excellent agreement and we can conclude that,with appropriate choice of wavelength and film material, the films can provide a measurement of absorbed dose to within $5 \%$. 

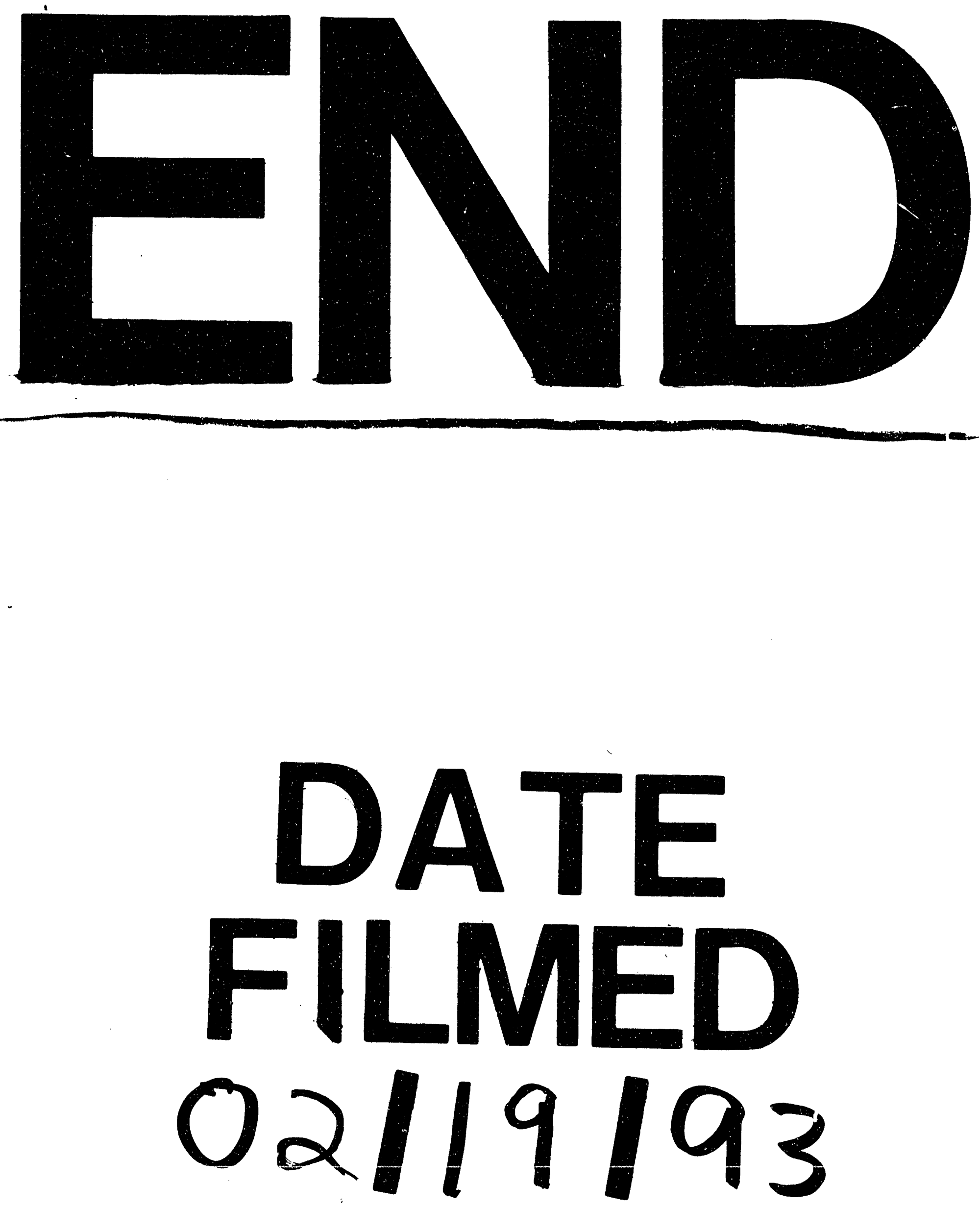
